\section{Mônica Nunes}

Colégio Martin Luther, Estrela/RS

E-mail: monicanunes.150@gmail.com

(D) http://orcid.org/0000-0002-8022-9766

\section{Fernanda Wanderer}

Universidade Federal do Rio Grande do Sul, UFRGS

E-mail: fernandawanderer@gmail.com

(D) http://orcid.org/0000-0002-8198-7104

Recebido em: 27/09/2017

Aprovado em: 16/09/2018

\section{Escola e as relações étnico-raciais: uma análise sobre enunciações de alunos}

\author{
Mônica Nunes \\ Fernanda Wanderer
}

\section{Resumo}

O artigo examina enunciações de alunos de uma escola pública gaúcha sobre os marcadores étnico-raciais que operam na instituição e na cidade onde residem: um município pertencente a uma região de colonização alemã. Como aportes teóricos, o estudo sustenta-se em teorizações do campo pós-estruturalista sobre raça, etnia e a constituição do sujeito. O material de pesquisa é constituído por entrevistas e questionários respondidos por discentes de uma turma do 80 ano do Ensino Fundamental. Em termos metodológicos, foi realizada uma etnografia, sendo os dados escrutinados na perspectiva da análise do discurso, como proposto por Michel Foucault. O exame do material mostrou que os estudantes negros não reconhecem sua negritude, autodenominando-se como "moreno" ou "escurinho". Além disso, os alunos negam a existência de racismo na escola, mesmo afirmando que práticas racistas são vivenciadas no município.

Palavras-chave: Etnografia. Michel Foucault. Raça/etnia. 
Abstract

Keywords:

Ethnography.

Michel Foucault.

Race/ethnicity.

\section{School and ethnic-racial relations: an analysis of student's statements}

The article examines the statements made by students of a public school in the state of Rio Grande do Sul about ethnic and racial markers operating in the institution and the city where they live: a municipality belonging to a region of German colonization. As theoretical contributions, the study is based on theories of the post-structuralist field on race, ethnicity and the constitution of the subject. The research material surveyed consists of interviews and questionnaires answered by students of a group of the 8th year of Elementary School. In methodological terms, an ethnography was performed, the data being scrutinized from the discourse analysis perspective, as proposed by Michel Foucault. The analysis showed that black students do not recognize their blackness, calling themselves "brown" or "darkish". In addition, students deny the existence of racism in school, even stating that racist practices are experienced in the municipality.

\section{Resumen}

\section{Palabras clave:}

Etnografía. Michel Foucault. Raza/etnia.
Escuela y relaciones étnico-raciales: un análisis sobre enunciaciones de alumnos

El artículo examina enunciaciones de alumnos de una escuela pública gaucha sobre los marcadores étnico-raciales que operan en la institución y en la ciudad donde residen: un municipio perteneciente a una región de colonización alemana. Como aportes teóricos, el estudio se sustenta en teorizaciones del campo post-estructuralista sobre raza, etnia y la constitución del sujeto. El material de investigación escrutado está constituido por entrevistas y cuestionarios respondidos por alumnos de una clase del $8^{\circ}$ año de la Enseñanza Fundamental. En términos metodológicos, se realizó una etnografía, siendo los datos escrutados en la perspectiva del análisis del discurso, como propuesto por Michel Foucault. El análisis mostró que los estudiantes negros no reconocían su negritud, autodenominándose como "moreno" o "escurinho". Además, los alumnos niegan la existencia de racismo en la escuela, aun afirmando que prácticas racistas son vivenciadas en el município. 


\section{Introdução}

$\mathrm{O}$ artigo discute questões relacionadas aos tensionamentos étnico-raciais na área da Educação. Em especial, nosso intuito é examinar enunciações de alunos dos Anos Finais do Ensino Fundamental sobre os marcadores étnico-raciais que operam na escola e na cidade onde residem: o município de Estrela, pertencente ao Vale do Taquari (RS), uma região fortemente vinculada aos processos de colonização alemã. Como aportes teóricos, o estudo sustenta-se em teorizações contemporâneas sobre raça, etnia e a constituição do sujeito, como analisado por Michel Foucault.

No cenário contemporâneo, questões vinculadas à raça e etnia se potencializaram e passaram a ser problematizadas e discutidas em vários setores da sociedade, como na mídia, nas redes sociais, nos postos de trabalho, nas escolas e em políticas públicas. Em efeito, desde a redemocratização do Brasil, ocorrida em 1985, os movimentos sociais, em especial o Movimento Negro, alcançaram espaço frente ao poder público e, aos poucos, provocaram transformações sociais, culturais e políticas ligadas às relações raciais, através das Políticas Afirmativas. Entre estas, podemos citar a Lei 10.639, a Lei de Cotas no Ensino Superior e o Estatuto da Igualdade Racial.

Especificamente na área da Educação, a partir da Lei n ${ }^{0}$ 10.639, promulgada em 2003, passou a ser obrigatório nas escolas de Ensino Fundamental e Médio o ensino da História e cultura africana e afrobrasileira. Assim, foram desencadeadas discussões acerca da importância de dar visibilidade afirmativa no cotidiano escolar à história e à cultura das diferentes etnias presentes no Brasil. Esta Lei foi criada em um contexto de implementação de Políticas Afirmativas para os segmentos sociais desfavorecidos no país e inaugurou a discussão do papel pedagógico da escola de incluir as questões da diferença étnico-racial, mas também da diferença religiosa, territorial, de gênero, da deficiência, entre tantas outras possibilidades, na construção de seus currículos.

Apesar dessas importantes conquistas, ainda percebe-se uma grande desigualdade racial no país, evidenciada, por exemplo, em estatísticas produzidas pelo IPEA (Instituto de Pesquisa Econômica Aplicada) e IBGE (Instituto Brasileiro de Geografia e Estatística). Dados recentes divulgados pelo IPEA (MARGUTI et al, 2017) mostraram que a vulnerabilidade social de um cidadão brasileiro está fortemente ligada à cor de sua pele. Mesmo apresentando alguns avanços importantes, há um abismo social entre brancos e negros, sendo que para estes as condições de educação, saúde e moradia são mais difíceis de alcançar do que para aqueles. Na área da Educação, indicadores do IBGE (2016) expressam que, em um período de dez anos (2005 a 2015), mesmo tendo dobrado o número de negros cursando o ensino superior, somente $12,8 \%$ dessa parte da população frequentou esse nível, enquanto que entre os brancos o índice é de 26,5\%. Essa diferença explica-se, em parte, pelas altas taxas de evasão e repetência dos alunos negros no Ensino Fundamental e Médio. 
Na região onde foi realizado este estudo - o Vale do Taquari, no Rio Grande do Sul - essas desigualdades também estão presentes. Observa-se que dentre as pessoas negras e pardas, uma minoria ocupa a classe média e alta da população. Os moradores negros, em sua maioria, trabalham como empregados domésticos, na construção civil, em ateliê de calçados e indústrias, onde se exige mais força física e recebe-se remuneração menor do que, por exemplo, nos setores do comércio e da prestação de serviços especializados (ANJOS, 2012).

Essas diferenças não podem ser tomadas como um fator recente. Inspiradas em Foucault, nas formas de pensar e fazer história, recorremos a alguns elementos do passado na tentativa de evidenciarmos a constituição dessas diferenças entre brancos e negros no Vale do Taquari. Autoras como Rago (2006) destacam que, para Foucault, sua relação com a história é sustentada a partir de um problema do presente. E, ainda, “[...] se o presente não é apenas o contemporâneo, é necessário fazer uma história do presente, quer dizer, reativar a carga do passado que está presente no presente.” (RAGO, 2006, p.4). Nesse sentido, a compreensão acerca dos modos de ser branco e negro na Região, que carrega as marcas da colonização portuguesa e da imigração alemã, está relacionada ao fato de reativarmos essa "carga do passado que está presente no presente".

A discussão que realizamos, nesta pequena introdução, não tem a pretensão de reescrever uma possível "História" dos negros na Região, mas apenas rearranjar fragmentos de algumas histórias de modo que se coloquem em evidência os tensionamentos étnico-raciais que acompanharam este território desde o início de seu povoamento, em 1855. Autores como Witt (2014) e Tramontini (2000) destacam que muitos historiadores brasileiros, no final do século XIX e início do século XX, omitiram ou ignoraram informações sobre a resistência e a participação do negro na história do Rio Grande do Sul. Os jornais da época, por sua vez, limitavam-se a publicar suicídios, fugas, assassinatos e punições.

Nesse sentido, grande parte das publicações sobre o Vale do Taquari (FERRI, 1991; HESSEL, 1983) seguem o modelo da historiografia tradicional a respeito da imigração alemã e a relevância deste grupo, em especial, para a garantia do progresso e desenvolvimento da Região (KREUTZ, 1991; RAMBO, 1994). Estes textos ressaltam a importância dos alemães para o desenvolvimento do território e os apresentam como um grupo regular, marcado pela manutenção dos costumes da sua região de origem, ignorando suas especificidades e os modos como lidavam com outros grupos, como os negros.

Essa questão é discutida por autores como Mugge e Moreira (2012) e Witt (2014) que, em seus trabalhos, analisam a relação que os imigrantes alemães estabeleceram com escravizados no decorrer do século XIX. Apontam que não deveria causar surpresa a associação entre as temáticas da imigração europeia e a escravidão, visto que quando ocorreu a chegada dos primeiros imigrantes alemães ao Rio Grande do Sul, a escravidão era economicamente lucrativa e moralmente aceita. Porém, segundo os autores, a historiografia fez parecer que a cultura dos imigrantes europeus não sofreu influência do meio 
escravocrata em que se inseriram. "Os imigrantes alemães (e seus descendentes) seriam arautos do trabalho manual, livre e morigerado, imunes às ânsias de seus vizinhos quanto à vontade de possuir escravos" (MUGGE E MOREIRA, 2012, p. 176). Evidencia-se o fato de que os imigrantes alemães também possuíam escravos negros, demonstrando que agiam de acordo com os padrões da época, diferentemente das representações sociais que se construíram sobre eles.

Estudos recentes como os de Wenschenfelder (2012) e Wanderer (2014), apoiados no pensamento de Michel Foucault, problematizam as relações étnico-raciais em regiões do Rio Grande do Sul fortemente marcadas pela colonização alemã, como os Vales do Rio Pardo e Taquari. Wenschenfelder (2012), quando se refere à historiografia de cidades como Santa Cruz do Sul e Venâncio Aires, pertencentes ao Vale do Rio Pardo, que é muito próximo, geograficamente, ao Vale do Taquari, destaca a presença de uma narrativa identitária que valorizou os colonos alemães e acabou por ignorar a presença de outros grupos étnicos, como os negros.

Já o trabalho de Wanderer (2014), focado nas tensões étnico-raciais que constituíram subjetividades específicas para alunos de Estrela que frequentavam uma escola rural no período da Campanha de Nacionalização (1937-1945), mostra que as relações entre brancos e negros eram marcadas pelo preconceito e desigualdades. Nas entrevistas realizadas pela autora com homens e mulheres que estudaram naquele período, foram recorrentes enunciações dizendo que os alunos negros foram aceitos na escola para amenizar os efeitos da fiscalização do governo, que exigia que as aulas fossem direcionadas à promoção dos elementos nacionais e, portanto, não enaltecessem elementos de outras culturas, no caso, a germânica. Naquele contexto, os negros também eram aceitos na escola para ensinar a língua portuguesa aos colegas, os quais, em suas famílias, só falavam em alemão. A pesquisa mostra que as discriminações raciais impediam o acesso das crianças negras à escola antes do período da Campanha de Nacionalização. Porém, a partir do final da década de 30, com a efetivação dos decretos da Campanha, as crianças negras passaram a frequentar a escola, mas, a todo instante, eram posicionadas como "burras" ou "causadoras de pequenos furtos". Apoiando-se em Hardt e Negri, Wanderer argumenta, então, que operava nas escolas um mecanismo de inclusão diferenciada: todas as crianças (brancas e negras) entravam na escola, no entanto, as relações entre elas, bem como o trabalho pedagógico realizado, posicionavam de diferentes formas brancos e negros.

Os estudos acima mostram que, em nosso país, a produção de saberes sobre as pessoas negras evidencia marcas como não-reconhecimento, silenciamento, invisibilidade e inferiorização (SILVA, 2007; WESCHENFELDER, 2012). Em especial, o estudo de Wanderer (2014) discute o quanto a escola está diretamente implicada com a produção de significados sobre os diferentes grupos étnicos, constituindo subjetividades específicas para os alunos (brancos, negros, indígenas) que a frequentam. 
Nossa pesquisa, realizada na mesma cidade, Estrela-RS, segue na esteira desse trabalho, analisando enunciações de alunos sobre as questões étnico-raciais. A diferença encontra-se, porém, no espaço-tempo examinado: enquanto Wanderer (2014) investigou esses processos no período da Campanha de Nacionalização, nosso trabalho está focado no tempo presente, em uma escola pública municipal que atende diferentes grupos étnicos, incluindo os haitianos que, a partir de 2012, chegaram na Região e provocaram novas e complexas relações entre os moradores das cidades e seus novos habitantes.

A migração haitiana, segundo dados da Fundação Getúlio Vargas (2017), é considerada o maior fenômeno migratório da década para o Brasil, sendo a Região Sul a mais procurada. As razões apontadas por estudiosos como Barbosa (2015), Uebel e Ruckert (2016) e Diehl (2016) para essa grande busca pelo Rio Grande do Sul e pela Região do Vale do Taquari estão associadas às dificuldades decorrentes do terremoto que assolou o país em 2010, aliado a um conjunto de vulnerabilidades que marcam a população daquele país: instabilidade política, mazelas sociais e econômicas e as catástrofes ambientais. Além disso, cabe mencionar a forte influência de redes de apoio, ou seja, migrantes que se deslocam e procuram por conhecidos ou amigos que já estão na nova forma de vida.

É neste contexto, brevemente apresentado, que se insere a investigação realizada que gerou a escrita deste artigo. Na próxima seção, será apresentada a metodologia empregada e os materiais de pesquisa reunidos.

\section{Metodologia e material de pesquisa}

A parte empírica da investigação foi realizada em uma escola municipal da cidade de Estrela-RS, no ano de 2016. A instituição atende o maior número de alunos da cidade e enfrenta problemas que se fazem presentes no cenário educacional: violência, pouca relação entre a escola e os pais dos alunos, evasão e repetência. Este trabalho foi realizado em uma turma do $8^{\circ}$ ano, formada por 19 alunos que frequentavam a escola no período diurno. Essa escolha não foi aleatória. Segundo relato da direção, era a que tinha o maior número de negros naquele período.

O início do trabalho de campo envolveu contatos com a Secretaria Municipal de Educação e, após sua aprovação, a direção da escola foi contatada para perguntarmos sobre a disponibilidade de realizar a parte empírica do estudo com os alunos. Cabe ressaltar que, de acordo com as normas de ética nas pesquisas em educação, a direção assinou o Termo de Assentimento da Instituição e os responsáveis por todos os alunos entrevistados assinaram o Termo de Consentimento Livre e Esclarecido, após serem informados sobre os objetivos da pesquisa.

A investigação envolveu técnicas de inspiração etnográfica, como diário de campo, entrevistas, observações e aplicação de questionários. A emergência da pesquisa de caráter etnográfico nas escolas é um fenômeno recente. Segundo Green, Dixon e Zaharlick (2005), o reconhecimento da etnografia como 
abordagem de pesquisa para os problemas e as investigações pertinentes à educação iniciou na metade do século XX. As autoras afirmam que a tarefa do etnógrafo dentro da escola é apontar "[...] as maneiras pelas quais os membros do grupo estudado percebem sua realidade e seu mundo, e como, por intermédio de suas ações (e interações) constituem seus valores, crenças, ideias e sistemas simbólicos significativos." (GREEN; DIXON; ZAHARLICK, 2005, p. 13). Por outro lado, fazem um alerta sobre os cuidados no momento da investigação ao assumir essa abordagem de pesquisa, entre os quais estão não entrar no ambiente escolar com uma lista de itens predefinida ou com questões e hipóteses predeterminadas, e não projetar um esquema de observação que defina a priori todos os comportamentos ou eventos que serão registrados.

O trabalho de campo envolveu diferentes estratégias, que se configuraram no decorrer da investigação. Ao todo, foram oito meses em que estivemos envolvidas com o objeto de estudo, realizando movimentos como: observações de aulas com registros no Diário de Campo, entrevistas com quatro alunos e aplicação de um questionário. Foram observadas aulas que ocorriam nas quartas-feiras, uma vez que este era o dia disponível para frequentarmos a escola. Buscamos, sempre, permanecer na turma, observando as aulas e, mais do que isso, atentamos para os diálogos e conversas que ocorriam entre os estudantes.

Essas observações foram registradas no Diário de Campo. Estamos cientes de que essa descrição sempre corresponderá a uma interpretação. Nesse sentido, Geertz (1989) nos lembra que toda descrição etnográfica é, sempre, a descrição de quem descreve, e não a de quem é descrito. Portanto, por mais inserido que o investigador esteja na cultura que deseja analisar ou no cotidiano dos sujeitos que pretende descrever, seu trabalho corresponde ao que ele próprio julga como relevante para ser interpretado a partir dos aportes teóricos que utiliza.

A seleção dos alunos entrevistados, num primeiro momento, foi definida pelo marcador étnicoracial, sendo escolhidos uma aluna e um aluno negros. Posteriormente, outros foram entrevistados, desta vez estudantes brancos. As entrevistas foram realizadas durante o período de aulas, conforme sugestão da direção, visto que os alunos não possuem o hábito de frequentar a escola em outro turno. Os encontros duraram, em média, meia hora cada um. Nosso propósito, era "mapear" o contexto dos alunos, a fim de identificar a forma pela qual eles se nomeiam e como interagem em seu mundo. Foram feitas perguntas sobre a família, sobre seus gostos, sobre a relação com os colegas, amigos e moradores do bairro e da cidade, bem como sobre a entrada de alunos haitianos na escola e possíveis tensionamentos étnico-raciais.

As entrevistas, de acordo com Silveira (2002, p. 120), são eventos discursivos, produzidos não só pela dupla entrevistador/entrevistado, mas também "pelas imagens, representações, expectativas que circulam - de parte a parte - no momento e situação de realização das mesmas e, posteriormente, de sua escuta e análise". Foi possível identificar que as enunciações dos alunos não eram dados prontos, e que 
sua significação dependia de uma análise minuciosa. Escutando as gravações, percebemos claramente a oscilação entre familiaridade, objetividade, aproximação e distanciamento, no jeito como eram conduzidas as perguntas, ora deixando "escapar" um comentário pessoal, ora falando de uma forma mais distanciada com o entrevistado. Portanto, conforme Silveira (2002, p. 126), “[...] esses encontros não tinham nada de angelicais.”. Se, por um lado, os entrevistadores estão em uma posição que se imagina que são eles quem fazem as escolhas e tomam as decisões, ficou evidente que muitas vezes eram os alunos que direcionavam a entrevista, ora com silêncios, ora com respostas que "fugiam" do assunto, ora dando um fim às questões discutidas.

O material de pesquisa reunido envolveu também questionários aplicados com todos os alunos da turma. As questões presentes abordaram tópicos como: descrições do modo de ser enquanto jovem aluno; casos de bullying que já sofreu ou conheceu; atitudes racistas na escola e na cidade. Os questionários foram respondidos individualmente, durante uma das aulas em que estivemos presentes.

A estratégia analítica utilizada para operar sobre os materiais é a análise do discurso, na perspectiva de Michel Foucault (2009). Na entrevista sobre o lançamento da obra "A Arqueologia do saber", o filósofo buscou explicar quais são os objetivos da análise do discurso, deixando evidente que não se trata puramente de descrever um discurso ou buscar fatos "escondidos", como se algo devesse ser escavado. "Tento, ao contrário, definir relações que estão na superfície dos discursos; tento tornar visível o que só é invisível por estar muito na superfície das coisas.” (FOUCAULT, 2000, p.56).

Seguindo o entendimento de Veiga-Neto (2014, p. 89), Foucault não vê "a linguagem como um instrumento que liga o nosso pensamento à coisa pensada, ou seja, como um instrumento de correspondência e como formalização da arte de pensar", mas "assume a linguagem como constitutiva do nosso pensamento e, em consequência, do sentido que damos às coisas, à nossa experiência, ao mundo". Seguindo essa perspectiva, um dos conceitos principais da obra de Foucault é a produtividade do discurso na constituição de objetos, de ideias e daquilo que somos.

Inspirando-se em Foucault, Fischer (2012) explica que, no seu entendimento, a análise do discurso trata basicamente da análise dos enunciados. Sobre descrever enunciados, ela afirma: "[...] significa apreender as coisas ditas como acontecimentos, como algo que irrompe num tempo e num espaço muito específicos, ou seja, no interior de uma formação discursiva.” (FISCHER, 2012, p. 101). E completa: “[...] esse feixe complexo de relações [é] que 'faz' com que algumas coisas possam ser ditas (e recebidas como verdadeiras) num certo momento e num lugar.” (FISCHER, 2012, p. 101).

Mas de que forma analisar as enunciações dos alunos nas entrevistas e nos questionários? Qual é o procedimento que Foucault nos recomenda? Para ele, de acordo com Fischer (2012, p. 74), “[...] nada há por trás das cortinas, nem sob o chão que pisamos. Há enunciados e relações, que o próprio discurso põe em funcionamento. Analisar o discurso seria dar conta exatamente disso: de relações históricas, de 
práticas muito concretas, que estão 'vivas' nos discursos.". Seguindo a inspiração foucaultiana, analisamos as enunciações produzidas pelos alunos não no sentido de encontrar o que está oculto, mas de dar ênfase a certos enunciados que costumam ser esquecidos ou ignorados. O resultado dessa operação será apresentado na próxima seção.

\section{As relações étnico-raciais}

Michel Foucault (1995), um dos filósofos mais utilizados nas pesquisas contemporâneas da área da Educação (AQUINO, 2013), dedicou-se a examinar, entre outros, processos vinculados à constituição do sujeito. Em "O sujeito e o poder", Foucault (1995, p.231) afirma que é o sujeito o tema geral de suas pesquisas, expressando que o objetivo de sua obra foi "criar uma história dos diferentes modos pelos quais, em nossa cultura, os seres humanos tornaram-se sujeitos". Fischer (2012) apresenta duas razões pelas quais Foucault tem o sujeito e as diversas formas de assujeitamento como o tema geral de suas investigações. A primeira é o entendimento de que os mecanismos de sujeição do indivíduo não constituiriam um momento final, “[...] mas sim processos circularmente relacionados com outras formas de dominação, de tal forma que um ou outro desses tipos de dominação poderia prevalecer, conforme o momento histórico." (FISCHER, 2012, p. 56). A segunda razão seria a ideia de que o Estado ocidental moderno alcançou "[...] uma combinação complexa de técnicas de individualização e procedimentos totalizantes [...]" (FISCHER, 2012, p. 56).

Dessa forma, seguindo os argumentos de Foucault, no Estado ocidental moderno estaria prevalecendo um poder pulverizado, presente em todas as relações e em todos os lugares. Um poder que atinge o cotidiano imediato das pessoas, "preocupado com o bem-estar da população e a saúde de cada um em particular, um poder que se reveste de bondade e sincera dedicação a toda a comunidade" e por isso não tem condições de se exercer "[...] senão munindo-se de toda a informação sobre cada grupo, sobre o que pensam e sentem todos os indivíduos e como eles podem ser mais bem dirigidos." (FISCHER, 2012, p. 56). Seguindo esse entendimento, os sujeitos são resultado de um processo que se dá no interior das redes de poderes que os capturam, dividem, classificam.

Nesse sentido, Foucault ampliou a análise de como o indivíduo torna-se sujeito. Discute a subjetividade entendendo essa palavra como a maneira pela qual o sujeito se constitui através das práticas de si, nas quais ele se relaciona consigo mesmo. Mas alerta: "essas práticas não são, entretanto, alguma coisa que o próprio indivíduo invente". E explica: "São esquemas que ele encontra em sua cultura e que lhe são propostos, sugeridos, impostos por sua cultura, sua sociedade e seu grupo social" (FOUCAULT, 2010, p. 276).

Os processos de constituição do sujeito, segundo Foucault, passam pelos processos de objetivação e subjetivação. Estes processos são contínuos de ida e vinda entre o interior e o exterior, entre o eu e o 
outro. A objetivação corresponderia à construção e identificação de representações sociais e coletivas. Conforme Fonseca (2003, p. 35), esse processo constrói e mantém funções sociais a serem ocupadas pelos sujeitos a partir de "formas estáveis do visível e do enunciável". A subjetivação corresponderia a processos pelos quais o indivíduo se identifica ou não com essas objetivações, essas representações, ou a forma como ele se identifica às suas singularidades.

A parte da obra em que Foucault trabalha o conceito de subjetivação é classificada por Veiga-Neto (2014) como o domínio foucaultiano da ética. Contudo, o autor salienta que a ética, entendida "[...] como cada um se vê a si mesmo [...]" (VEIGA-NETO, 2014, p.82), só pode ser colocada em movimento a partir dos eixos dos outros dois domínios: o "ser-saber" e o "ser-poder”. Em outras palavras: “[...] o sujeito é um produto, ao mesmo tempo, dos saberes, dos poderes e da ética.” (IBIDEM). Com ênfase na subjetivação, Foucault escreve sobre um conjunto de tecnologias, destacando-se as tecnologias do eu que foram reunidas nos segundo e terceiro volumes da obra "História da sexualidade".

Em relação ao terceiro domínio, Larrosa (2011) traz importantes contribuições para a área educacional, exemplificando que podemos situar a produção pedagógica do sujeito fundamentalmente do ponto de vista da subjetivação. O autor afirma que as práticas pedagógicas constituem e medeiam certas relações determinadas do sujeito aluno consigo mesmo. Seguindo Larrosa (2011, p. 57), é importante salientar que a "[...] pedagogia não pode ser vista como um espaço neutro ou não problemático de desenvolvimento ou de mediação [...]" onde os alunos simplesmente aprendem a observar-se, julgar-se, narrar-se ou dominar-se, mas "como produzindo formas de experiência de si nas quais os indivíduos podem se tornar sujeitos de um modo particular".

Relacionando esta investigação com a discussão até aqui empreendida, diríamos que os alunos (brancos, negros, indígenas, entre outros) são produzidos pelas diferentes experiências dentro e fora da sala de aula, pelas diferentes linguagens por meio das quais são nomeados, descritos, tipificados. Há, portanto, uma constante luta entre discursos que pretendem capturar os sujeitos, os quais são interpelados por diversas narrativas, se transformando, ao mesmo tempo, de acordo com as narrativas que eles próprios produzem sobre suas histórias de vida. Nesse processo, complexo e instável, a escola constitui-se como o espaço em que os alunos articulam muitas posições, rejeitam e abandonam algumas e assumem outras que lhes conferem provisoriamente um sentido de pertencimento a um determinado grupo social.

Analisando o material de pesquisa reunido, percebemos um grande tensionamento presente nas formas pelas quais os alunos negros são subjetivados dentro e fora da escola. Esse tensionamento nos permitiu construir uma analítica que evidencia três resultados para esta pesquisa, os quais estão articulados. O primeiro deles refere-se à autodenominação. Nenhum dos alunos pertencentes ao grupo que nós, inicialmente, reconheceríamos como sendo negros, se autodenominou dessa forma. A maior 
ocorrência foi nomearem-se "morenos". Isso ocorreu, principalmente, nas respostas de uma das questões do questionário, a qual referia-se a uma descrição de cada estudante:

$\mathrm{Eu}$ sou uma menina de pele de cor morena, meus cabelos são pretos, lisos e longos. Eu gosto de jogar vôlei e eu penso em fazer uma faculdade e ser bióloga marinha [grifos nossos].

Sou alto, moreno e tenho cabelo crespo. Gosto de ouvir música, jogar videogame, praticar esportes, gosto de dar um rolé com os parça e andar de skate [grifos nossos].

Eu sou uma menina que tem cabelo cacheado, meio morena, não sou muito alta, e sou magra, tenho olhos castanhos claros. Gosto muito de amizades novas, de comer doces e músicas internacionais [grifos nossos].

Sou uma menina meio escurinha, tenho olhos verdes, sou muito "oito ou oitenta", não gosto de "ah, talvez, não sei", sou muito perfeccionista. Gosto muito mesmo de passear e de passar minha tarde nas redes sociais: Whatsapp, Instagran, Snapchat e a que sou mais viciada: You Tube [grifos nossos].

No primeiro excerto, a aluna refere-se especificamente à cor de sua pele, e indica que se percebe como "menina de pele de cor morena". O segundo, por sua vez, se autodenomina, simplesmente, "moreno", termo que, no contexto, pode ser entendido como referindo-se à cor de sua pele ou, de maneira mais ampla, à de seu cabelo. Já os demais estudantes narraram-se como "meio" moreno, uma palavra que, de certa maneira, parece corresponder a mais uma forma de, como afirmou Silva (2007), "amolecer" a rigidez das polarizações. As alunas usam a palavra "meio", um advérbio de intensidade que, no caso, atenua o adjetivo empregado na sequência: "meio morena", "meio escurinha" (neste último caso, o diminutivo -inha é outro atenuante). Dessa forma, demonstram que não se reconhecem simplesmente como "morenas", mas como pertencentes a um grupo menos "escuro". Essa dificuldade de identificar-se com um grupo étnico-racial é própria dos tensionamentos relativos a esta questão, conforme explicado por Kaercher (2010).

Durante as observações de aulas ocorreu um diálogo que merece destaque. Um dos alunos disse que era moreno. E continuou: "Não sei por que me chamam de preto. Eu não sou preto, sou moreno. Preto é quando não dá para enxergar". E, na sequência, afirmou: “os pretos são os haitianos". Percebemos, novamente, que o pertencimento étnico-racial se constitui em um processo envolto em tensões que frequentemente geram negação ou rejeição ao sentimento de pertença a um determinado grupo. Nesse caso, mais uma vez, emerge a enunciação de que os alunos da escola não são negros, e a justificativa está na comparação que estes realizam com os haitianos, cuja cor da pele identificam como sendo "mais escura".

Nas falas dos alunos é possível notar um traço bastante característico da questão racial no Brasil. Diferentemente do que acontece em outros países, nos quais as diferenças raciais limitam-se a grandes 
grupos, como brancos, negros e amarelos, no Brasil criaram-se diversas outras denominações para, supostamente, referir-se às muitas configurações raciais provenientes do complexo processo de miscigenação que produziu o nosso povo. Silva (2007), no entanto, chama a atenção para o fato de que há, na criação dessas novas denominações, um aspecto igualmente cultural, não relacionado apenas à cor da pele, mas contendo uma acepção que diz respeito às representações sociais, e que, em certo sentido, indicam as tensões étnico-raciais presentes em nosso país. Segundo ele, merece justamente "[...] atenção especial a categoria 'moreno(a)', 'claro(a)' ou 'escuro(a)' [...]”' (SILVA, 2007, p. 74). Isso porque, de acordo com o autor, o "moreno não apenas amolece a rigidez das polarizações, mas também implica um processo de deslizamento do 'preto' para o 'branco"”. Nesse sentido, percebe-se, nessa visão, a ideia de que ser negro é algo negativo, enquanto ser "moreno" reduz essa negatividade.

Como as histórias pessoais desses alunos estavam marcadas pelos tensionamentos étnico-raciais, uma das perguntas do questionário aplicado era "O que você entende por racismo?". As respostas mostram diferentes pontos de vista acerca da questão: "Eu sei que racismo é feito por pessoas que não têm caráter, que racismo é desnecessário e que normalmente quem sofre racismo são os morenos". Outro aluno respondeu: "Sei que racismo é crime". A fala do primeiro aluno indica três dimensões importantes: em primeiro lugar, o aluno relaciona o racismo a um defeito de caráter de quem o pratica; em segundo, afirma que se trata de algo "desnecessário"; por fim, repete a designação de "morenos" para referir-se às pessoas que sofrem discriminação racial, evitando utilizar-se da palavra "negros". Dessa forma, reforça-se a ideia de que há, também, entre os alunos desta escola, uma tendência para "amolecer a rigidez das polarizações", mediante o uso do termo "moreno". Já a resposta do outro aluno mostrou-se, de certa forma, capturada por marcas de caráter político e jurídico. Em sua enunciação, percebem-se as capilaridades do poder, mais precisamente do poder jurídico, cujo discurso, como visto, é capaz de capturar inclusive os adolescentes em questão.

Hardt e Negri (2004) utilizam o termo racismo imperial para argumentar que, ao contrário do que imaginamos, o racismo não diminuiu, visto que, de acordo com eles, apesar de práticas como o apartheid e a escravidão terem deixado de existir, o racismo passou a adotar novas estratégias, mais sutis, infiltrando-se disfarçadamente em diversas práticas sociais. Os autores afirmam que "[...] o racismo não retrocedeu, e que na realidade progrediu no mundo contemporâneo, tanto em extensão como em intensidade. Só parece ter declinado porque suas formas e estratégias mudaram.” (2004, p.210).

$\mathrm{Na}$ configuração do racismo imperial, não estamos diante de uma oposição binária marcada pela cor da pele, e sim por questões que transcendem essa diferenciação. Para os autores (HARDT; NEGRI, 2004, p. 213) “[...] as diferenças biológicas foram substituídas por significadores culturais [...]. As diferenças são, portanto, não fixas e imutáveis, mas efeitos contingentes da história social [...]”. Isso significa que a "supremacia branca" não se configura apenas como a supremacia das pessoas de pele 
branca, mas daquelas que, além disso, pensam e se comportam de "modo superior", bem como têm os valores considerados "superiores", ou, como disse um dos alunos entrevistados, apresentam outros "gostos".

Os autores explicam que, na lógica do Império, “[...] a exclusão racial surge geralmente como resultado da inclusão diferenciada [...]" (HARDT; NEGRI, 2004, p. 215). Nesse sentido, as práticas racistas não funcionam por exclusão, pois “[...] nenhuma identidade é designada como o Outro, ninguém é excluído do domínio, não existe lado de fora [...]” (HARDT; NEGRI, 2004, p. 215). Assim, o racismo imperial atua por inclusão e subordinação: "A supremacia branca funciona, de preferência, primeiro atraindo a alteridade e depois subordinando as diferenças de acordo com graus de desvio da brancura." (HARDT; NEGRI, 2004, p. 215), o que se confirma quando os alunos se autodenominam "morenos", ou, em um grau menor de desvio da brancura, como "meio morenos".

O segundo resultado deste estudo diz respeito à discriminação racial presente na cidade de Estrela. Nas entrevistas, essa questão foi evidenciada quando os alunos foram questionados sobre a vivência de práticas racistas no município: "Junto com meu primo, que é negro, dentro do mercado. A dona do mercado começou a nos seguir achando que nós ia roubar alguma coisa. Nós nos indignemos e falemos umas verdades pra ela". Outro aluno, na mesma direção, explicitou: "Não tem motivo especial para ter racismo aqui [em Estrela], mas a gente consegue ver pela reação das pessoas quando a gente passa. Muitas vezes as pessoas te olham torto, ou elas começam a cochichar, ou alguma coisa assim”.

Nesse sentido, é importante notar o quanto o "olhar torto" e os comentários dessas pessoas podem deixar marcas na identidade dos sujeitos negros, isso porque, conforme Ramos, Santana e Santana (2011, p. 17): "É pelo olhar do outro que me constituo como sujeito. É a qualidade desse olhar que contribui para o grau de autoestima da criança [...]", no caso, os estudantes negros da escola. No excerto a seguir, um aluno relaciona o preconceito que percebe estar presente nas relações sociais da cidade à história da colonização do município. Segundo ele, "eu acho que os negros sofrem preconceito. Ainda mais que aqui em Estrela foi colonização alemã, então as pessoas não estão acostumadas com algo diferente. Isso vai melhorar com o tempo, com a cabeça das pessoas".

Nessa enunciação, fica evidente que o negro é o "diferente", assim identificado porque os descendentes de alemães se constituem como a norma. Conforme Silva (2007), nas regiões do Estado do Rio Grande do Sul marcadas pela colonização alemã, essa forma de vida estabeleceu-se como a norma que posiciona os indivíduos de outras etnias como sendo "os diferentes". Segundo ele, criou-se um “discurso mítico" fundador da identidade germânica. Nesse sentido, o autor destaca que "a naturalização da identidade cultural permite, assim, o estabelecimento de fronteiras culturais/étnicas fixas, coexistentes no mesmo espaço [...]" (SILVA, 2007, p. 125), como é o caso dos descendentes de imigrantes alemães e os negros. 
Para os estudantes entrevistados, os imigrantes haitianos sofrem discriminação inclusive dentro do bairro onde residem. No excerto abaixo, um aluno destaca que os haitianos não são vistos apenas como pessoas negras, mas que há, em sua negritude, algo "diferente":

Acho que [os haitianos] estão sofrendo bastante racismo. Porque, tipo, além deles, tá, eles são negros, mas de uma forma um pouco diferente, vamos dizer, e todo mundo faz chacota, "ah, olha só, quando acabar a luz não vamos ver mais ele", tipo, isso é uma coisa chata pra eles, e pra gente também, tipo, a gente acaba sentido por eles, daí isso é chato.

Evidencia-se que o racismo praticado contra os haitianos diz respeito ao fato de estes serem "mais negros". Dessa forma, pode-se traçar um paralelo entre essa situação e os tensionamentos étnico-raciais presentes em relação aos que se autodenominam morenos, bem como ao mito da democracia racial, pois fica claro que ela é uma criação discursiva. Ideia semelhante foi defendida por Schwarcz (1998), que reflete sobre o modo como o racismo está presente na vida privada dos brasileiros, bem como em sua intimidade. Segundo ela, na Pesquisa Nacional por Amostra de Domicílio consolidada em 1976, na qual os respondentes diziam qual era a sua cor sem que houvesse termos pré-estabelecidos, houve 136 denominações diferentes, o que a autora chamou de "aquarela do Brasil", e que corroborou suas ideias acerca do caráter íntimo e privado do racismo no país. Para a autora, a raça e a etnia dos sujeitos depende de uma série de elementos muito mais complexos do que um dado supostamente objetivo proveniente da observação da cor da pele, uma vez que esta não depende de uma "essência", mas da relação social e cultural entre diversos sujeitos que, continuamente, colocam-se comparativamente aos outros.

Silva (2007) explica que o advento da república no Brasil, no final do século XIX, elevou os negros à categoria de cidadãos, ou seja, a partir daquele momento, eles passaram a gozar da igualdade jurídica. Porém, na prática, não era isso o que se via. $\mathrm{O}$ autor afirma que as teses biodeterministas da época, como a eugenia e o higienismo, faziam com que o negro não fosse tratado como um igual, pois “[...] rasuravam seu status de cidadão.” (2007, p.42). Seguindo seus argumentos, as produções discursivas de inferioridade racial legitimaram a exploração por parte das classes dominantes e ainda repercutiram no imaginário dos brasileiros, os quais desejavam "embranquecer" para vislumbrar alguma chance de ascensão social.

Nesse contexto, surge a política de branqueamento. Conforme Schwarcz (2001, p. 43), no período abolicionista que culminaria com a libertação dos escravos, “[...] iniciou-se uma política agressiva de incentivo à imigração europeia, ainda nos últimos anos do Império, marcada por uma intenção também evidente de tornar o país mais claro.”. No final do século XIX, os intelectuais brasileiros, inspirados no ideário científico da época, pensavam que a miscigenação só “[...] teria sentido caso levasse ao branqueamento da nação, caso suprimisse as raças inferiores pela ação do sangue branco.” (SILVA, 2007, p. 38). 
O terceiro resultado desta pesquisa relaciona-se às práticas racistas na escola. Quando questionados sobre as tensões étnico-raciais no interior da escola, os alunos foram unânimes em afirmar que nela as práticas discriminatórias não ocorrem. Um dos alunos foi enfático: "Não! Não! Nunca vi! Nunca fizeram comigo! Nunca senti nada diferente, tipo em relação à minha cor”. Outro destacou: “Racismo, não, aqui [na escola] não tem racismo. Acho que todo mundo é aceito assim”. Contudo, é preciso observar algumas enunciações que carregam uma maior complexidade. $\mathrm{O}$ aluno abaixo refere-se ao fato de que a presença de negros na escola é pequena. Em sua fala, refere-se, ainda, aos que denomina como mulatos: "Nós somos amigos, mesmo tendo poucos negros, né? Tem até uns três ou quatro que são mulatos também, sabe!? Mas nada de preconceito [...] Daí todos aqueles lá são amigos faz tempo". O aluno explica que não há preconceito porque são todos "amigos", e isso porque estudam juntos "desde o primeiro ano". Dessa forma, vê-se que sua enunciação demonstra que a discriminação racial é evitada pelo fato de os alunos estudarem juntos durante vários anos, desde muito jovens.

Nos questionários, a maior parte das respostas apontou ideias muito semelhantes às desenvolvidas acima: "Que eu saiba não existe racismo na nossa escola, mas na nossa cidade existe, pois já vi várias pessoas sofrendo racismo ou algo parecido". "Eu acho que aqui na escola não existe racismo, pois quase todos nós somos iguais, pelo menos eu nunca vi". Tal como visto nas entrevistas, o primeiro aluno menciona duas realidades distintas: o racismo enfrentado na cidade e a ausência dele na escola. $\mathrm{O}$ segundo, por sua vez, procura explicar por que não há racismo na escola. Nota-se, em sua fala, que o racismo supostamente não existe na escola porque os alunos se identificam como pertencentes a um mesmo grupo étnico-racial: "pois quase todos nós somos iguais".

Por outro lado, há enunciações que apresentam perspectivas diferentes daquelas que apontam para a não existência de práticas de discriminação racial, como se vê nas falas a seguir: "Racismo existe em todo lugar, tanto na fila do supermercado, no banco, na rua, na escola, e os exemplos é só acompanhar as notícias". "Na minha escola, acho que é pouco racismo, é só quando o preto tem cabelo feio, daí acontece por isso". "Na minha cidade acho que não, nunca me deparei com algo assim". O primeiro aluno generaliza a presença do racismo em nossa sociedade, e cita alguns lugares para exemplificar sua ocorrência. Entre eles a escola e, portanto, na sua concepção, percebe o racismo presente também neste ambiente. O segundo aluno parece corroborar esta opinião, pois, ao afirmar que, na escola, há "pouco racismo", mostra que intui a existência de racismo neste ambiente, embora reconheça sua reduzida ocorrência. No entanto, é importante notar o que ele afirma na sequência, isto é, que o racismo ocorre "só quando o preto tem cabelo feio, daí acontece por isso". Nota-se que, nesse contexto, o racismo não diz respeito à cor da pele, mas a algo que os estudantes relacionam à "estética" do cabelo.

Uma situação semelhante foi encontrada por Ramos, Santana e Santana (2011, p. 20). Uma aluna entrevistada pelas pesquisadoras narrou seu sofrimento por usar o cabelo crespo no estilo Black Power. 
De acordo com elas, a entrevistada disse que não gostava de seu cabelo e o motivo seria porque o colega falava mal dele. Por isso, a aluna afirma: "se eu pudesse, teria um cabelo grande e liso igual de minha professora"'. As pesquisadoras informam que a estudante tem onze anos, e que a professora em questão é branca, de modo que a aluna, "[...] ao desejar parecer com sua professora acaba reforçando a ideia de positividade do estereótipo branco".

Podemos, por um lado, explicar a ausência de racismo na escola pelo modo como os alunos se descrevem. Eles não se reconhecem como negros, autodenominando-se "morenos" e "meio morenos". Logo, ao não se identificarem como negros, não se vê a possibilidade, num primeiro momento, de práticas de discriminação racial. Contudo, há a existência de tensionamentos, como ficou exemplificado no caso do aluno que se mostra incomodado ao chamarem-no de preto, pois se considera moreno. Ao mesmo tempo, estes mesmos alunos, que não se reconhecem como negros, relatam sofrer preconceito racial quando circulam em ambientes fora da escola. Essa diferença de percepção ocorre devido à produção da identificação racial, que é contingente e depende do contexto em que estamos inseridos. Conforme Kaercher (2010, p. 87):

A cor da pele é o fator que determina, para esse sujeito branco que julga, e para quase todos nós, negros e brancos educados dentro de uma pedagogia da racialização voltada para a construção de um determinado tipo de brancos e negros, um elemento que indica e, por fim, define quem é branco(a), quem é negro(a).

Para os alunos que participaram deste estudo, os "tipos" de brancos e negros parecem ser diferentes dos "tipos" de brancos e negros percebidos pelas pessoas de ascendência alemã que os discriminam na cidade, seguindo-os no interior dos mercados, olhando-os "torto" e "cochichando" na rua quando os veem passar. Para essas pessoas, os estudantes que participaram deste estudo são considerados negros, enquanto os mesmos não se consideram desta forma. Isso porque o contexto em que vivem aquelas pessoas é diferente do contexto em que vivem estes alunos.

Os descendentes de alemães têm a sua cor como marca de branquitude e, por conseguinte, consideram como negros todos aqueles que não correspondem à sua cor de pele, inclusive, portanto, os alunos referidos. Enquanto isso, estes, por sua vez, colocam em rasura a sua cor e, como vimos, consideram, por exemplo, os haitianos como sendo negros. Além disso, se autodenominam "morenos", numa forma de "amolecer a rigidez das polarizações", conforme Silva (2007). No mesmo sentido, Kaercher (2010, p. 87) afirma que "não é necessário um esforço muito grande para que possamos localizar um punhado de exemplos onde, por força dos modos como nos educou a pedagogia da racialização, temos dificuldade de lidar com a pertença racial [...]", como é o caso dos alunos em questão.

\section{Considerações finais}


Na seção que encerra este artigo, não temos a pretensão de apresentar possíveis conclusões, no sentido de indicarmos um "ponto final" ou resultados gerais que possam ser aplicados a outros contextos educacionais. Seguindo o referencial teórico adotado nesta investigação, estamos cientes de que nosso estudo gerou, apenas, algumas possibilidades de discutirmos e pensarmos mais sobre as formas pelas quais a temática étnico-racial se articula com o campo da Educação. Mesmo assim, consideramos pertinente destacar, ainda, pequenas questões que podem ser evidenciadas a partir do exposto neste trabalho.

Uma delas refere-se ao nosso lugar enquanto pesquisadoras. Ao longo da realização desta pesquisa, buscamos, a todo instante, estarmos atentas àquilo que acontecia na escola investigada a respeito das relações étnico-raciais, seguindo uma atitude que Veiga-Neto (2013) chamou de hipercrítica. Para ele, esta crítica consiste em "[...] um tipo de desconstrucionismo que faz da crítica uma prática permanente e intransigente até consigo mesma, de modo a estranhar e desfamiliarizar o que parecia tranquilo e acordado entre todos." (VEIGA-NETO, 2013, p.15). A prática da hipercrítica é um exercício delicado e complexo, uma vez que exige do pesquisador um olhar vigilante para que sua visão de mundo não se imponha a seu objeto de pesquisa, e que suas verdades não interfiram em sua análise. Da mesma forma que não podemos nos libertar de nosso próprio modo de ver o mundo, precisamos dar voz ao modo como os outros o veem.

Interessadas em dar visibilidade ao modo pelos quais os alunos de uma escola pública estão subjetivados, em especial pelos marcadores étnico-raciais, buscamos respaldo nas teorizações de Foucault, dado que, em grande parte de sua obra, o filósofo dedicou-se a mostrar de que maneiras nos constituímos como sujeitos. Para ele, o sujeito é entendido como um artifício da linguagem, uma produção discursiva e um efeito de relações de poder-saber. Enfim, a partir da obra de Foucault, pode-se dizer que “o sujeito passa a ser [...] aquilo que dele se diz." (MEYER; PARAÍ́SO, 2014, p. 29).

Sobre isso, nossa investigação mostrou três resultados, os quais estão diretamente implicados com as formas pelas quais os alunos se identificam e percebem as relações étnico-raciais na escola e na cidade onde residem. Em primeiro lugar, as enunciações examinadas mostraram um não-reconhecimento da negritude dos estudantes que preferem denominar-se como "morenos" ou "escuros". Este aspecto corroborou as afirmações de Silva (2007), quando menciona que, no Brasil, há um "amolecimento" da rigidez das polarizações, o qual se materializa em novas denominações, como é o caso do "moreno" e "meio escurinha". Para os discentes entrevistados, negros são apenas os haitianos, em função do tom mais escuro de sua pele. Além disso, a pesquisa destaca que os alunos negam a existência de racismo na escola, mesmo afirmando que práticas racistas são vivenciadas no município.

A partir desses resultados, outras questões podem ser destacadas. Uma delas é que nosso trabalho, de certa forma, ajuda a sustentar as discussões já empreendidas sobre os conceitos de "raça" e "etnia". De 
acordo com Meyer (2011, p.47), tais conceitos podem ser compreendidos como "[...] contingências históricas, produzidas umas em relação a outras, em contextos sociais específicos [...]”. São, assim, “[...] construções que se dão no interior dos processos sociais, resultados de uma relação de poder entre forças que se exercem tanto para a dominação como para a resistência [...]” (MEYER, 2011, p. 47). Ciente de que essas definições estão carregadas de tensionamentos políticos e atravessadas por relações de poder, nosso estudo procurou justamente entender como essas categorias operam no sentido de construir as subjetividades dos alunos. Assim, estivemos interessadas em analisar os modos pelos quais os alunos se identificam e se percebem como moradores de uma cidade marcada pela colonização alemã.

Ao apresentarmos alguns elementos da história do Vale do Taquari, foi possível assinalar que a historiografia oficial silenciou a participação dos negros no processo de formação da Região, sendo a colonização alemã imposta como a cultura dominante. Nesse sentido, mostramos de que modo essa dimensão histórica ainda produz efeitos nos tensionamentos étnico-raciais vivenciados pelos alunos que participaram desta pesquisa. Porém, podemos dizer que essas questões estão presentes em outros municípios do Estado do Rio Grande do Sul e do Brasil. Em relação à desigualdade racial ainda existente no país, Gomes (2003, p. 76) aponta que “[...] a classificação e a hierarquização racial ainda hoje existentes [...] passaram a regular as ações entre negros e brancos como mais uma lógica desenvolvida no interior da sociedade".

Por fim, ressaltamos que nesses tempos líquidos em que vivemos, a escola pós-moderna tem-se configurado como um espaço de problematização de algumas das grandes "verdades" que aceitamos e tomamos como naturais, sem questionamento. Assim, não temos como pensar a educação de modo desarticulado das questões da diferença, cultura, raça, etnia, gênero e tantas outras. Desta forma, consideramos que a pesquisa contribuiu abrindo espaço para narrativas dos alunos acerca das questões étnico-raciais. Isso possibilitou que os discentes refletissem sobre si mesmos e sobre questões mais amplas relativas à sociedade em que vivem. Esse exercício de questionamento, quem sabe, pode abrir espaço a outras possibilidades de pensarmos sobre a sociedade e sobre nós mesmos.

\section{Referências}

ANJOS, Gilson Luiz. (Re)Conhecimento e negritude: uma questão da educação? 2012. 90 f. Dissertação (Mestrado em Educação). Programa de Pós-Graduação em Educação, Faculdade de Educação, Universidade Federal do Rio Grande do Sul, Porto Alegre, 2012.

AQUINO, Julio Groppa. A difusão do pensamento de Michel Foucault na educação brasileira: um itinerário bibliográfico. Revista Brasileira de Educação, Rio de Janeiro, v. 18, n. 53, p. 301-324, 2013.

BARBOSA, Lorena S. Imigrantes Haitianos no Rio Grande do Sul: uma etnografia de sua inserção no contexto sociocultural brasileiro. 2015. 122 f. Dissertação (Mestrado em Ciências Sociais). Programa de Pós-Graduação em Ciências Sociais, Universidade Federal de Santa Maria, Santa Maria, 2015. 
DIEHL, Fernando. O fenômeno da estigmatização dos imigrantes haitianos em Lajeado no Rio Grande do Sul. Barbarói, Santa Cruz do Sul, n.47, p.90-106, 2016.

FERRI, Gino. História do rio Taquari-Antas. Encantado: Grafen, 1991.

FISCHER, Rosa Maria Bueno. Trabalhar com Foucault: arqueologia de uma paixão. Belo Horizonte: Autêntica, 2012.

FONSECA, Márcio Alves. Michel Foucault e a constituição do sujeito. São Paulo: EDUC, 2003.

FOUCAULT, Michel. O sujeito e o poder. In: DREYFUS, Hubert; RABINOW, Paul (Org.). Michel Foucault, uma trajetória filosófica: para além do estruturalismo e da hermenêutica. Rio de Janeiro: Forense Universitária, 1995, p. 273-295.

FOUCAULT, Michel. Michel Foucault explica seu último livro. Ditos e escritos II. Rio de Janeiro: Forense, 2000 p.145-152.

FOUCAULT, Michel. A ordem do discurso: aula inaugural no Collège de France. São Paulo: Edições Loyola, 2009.

FOUCAULT, Michel. História da Sexualidade II - O uso dos prazeres. Rio de Janeiro: Graal, 2010.

FGV. Fundação Getúlio Vargas. Haitianos no Brasil: hipóteses sobre a distribuição espacial dos imigrantes pelo território brasileiro. Rio de Janeiro: RJ, 2017. Disponível em: http://dapp.fgv.br/haitianos-no-brasil-hipoteses-sobre-distribuicao-espacial-dos-imigrantes-pelo-territoriobrasileiro/. Acesso em 26 de set. 2017.

GEERTZ, Clifford. Estar lá, escrever aqui. Diálogo, São Paulo, v. 22, n. 3, p. 58-63, 1989.

GOMES, Nilma Lino. Cultura negra e educação. Revista Brasileira de Educação, Rio de Janeiro, n. 23, p. 75-85, 2003.

GREEN, Judith L.; DIXON, Carol N.; ZAHARLICK, Amy. A etnografia como uma lógica de investigação. Educação em Revista, Belo Horizonte, n. 42, p. 13-79, 2005.

HARDT, Michael; NEGRI, Antonio. Império. 6. ed. Rio de Janeiro: Record, 2004.

HESSEL, Lothar. O município de Estrela: história e crônica. Porto Alegre: Editora da UFRGS,1983.

IBGE. Instituto Brasileiro de Geografia e Estatística. Características étnico-raciais da população. Brasília, DF: IBGE, 2008. Disponível em: <http://www.ibge.gov.br/ home/estatistica/populacao/caracteristicas_raciais/default_zip.shtm>. Acesso em 23 jul. 2016.

KAERCHER, Gládis Elise Pereira da Silva. Pedagogias da racialização ou dos modos como se aprende a "ter" raça e/ou cor. In: BUJES, Maria Isabel Edelweiss; BONIN, Iara Tatiana (Org.). Pedagogias sem fronteiras. Canoas: Ed. ULBRA, 2010. p. 85-91.

KREUTZ, Lúcio. O professor paroquial: magistério e imigração alemã. Porto Alegre: Editora da UFRGS, 1991. 
LARROSA, Jorge. Tecnologias do eu e educação. In: SILVA, Tomaz Tadeu da (Org.). O sujeito da educação: estudos foucaultianos. 8. ed. Petrópolis: Vozes, 2011. p. 35-86.

MARGUTI, Bárbara Oliveira et al. Relatório de pesquisa: a nova plataforma da vulnerabilidade social: primeiros resultados do índice de vulnerabilidade social para a série histórica da PNAD (2011-2015) e desagregações por sexo, cor e situação de domicílio. Brasília, DF: IPEA, 2017. Disponível em:

http://dapp.fgv.br/haitianos-no-brasil-hipoteses-sobre-distribuicao-espacial-dos-imigrantes-pelo-territoriobrasileiro/. Acesso em 26 de set. 2017.

MEYER, Dagmar Estermann. Das (im)possibilidades de se ver como anjo... In: GOMES, Nilma Lino; SILVA, Petronilha Beatriz Gonçalves (Org.). Experiências étnico-culturais para a formação de professores. Belo Horizonte: Autêntica, 2011. p. 51-69.

MEYER, Dagmar Estermann; PARAÍSO, Marlucy Alves (Org.). Metodologias de pesquisas pós-críticas em educação. 2. ed. Belo Horizonte: Mazza, 2014.

MUGGE, Miquéias Henrique; MOREIRA, Paulo Roberto. A fim de adquirir algum escravo, que possa aplicar ao serviço da lavoura nas terras que lhe foram destinadas: notas sobre imigração alemã e escravidão no Brasil meridional nos Oitocentos. MÉTIS: História \& Cultura, Caxias do Sul, v. 11, n. 22, p. 175-196, 2012.

RAGO, Margareth. A história do presente em Michel Foucault. In: ENCONTRO REGIONAL DE HISTÓRIA, 18., 2006, Assis. Anais... Assis: UNESP, 2006. p. 1-8. Disponível em: < http://www.anpuhsp.org.br/sp/downloads/CD\%20XVIII/pdf/

ORDEM\%20ALFAB\%C9TICA/Luzia\%20Margareth\%20Rago.pdf>. Acesso em: 11 jun. 2017.

RAMBO, Arthur Blásio. A escola comunitária teuto-brasileira católica. São Leopoldo: UNISINOS, 1994.

RAMOS, Aline Oliveira; SANTANA, Marise de; SANTANA, José Valdir Jesus de. Relações étnicoraciais no ambiente escolar: reflexões a partir de uma escola pública no município de Itapetinga/BA. Educação, Gestão e Sociedade, São Paulo, ano 1, n. 2, 2011.

SCHWARCZ, Lilia Moritz (Org.). História da vida privada no Brasil: contrastes da intimidade contemporânea. São Paulo: Companhia das Letras, 1998.

SCHWARCZ, Lilia Moritz. Racismo no Brasil. São Paulo: Publifolha, 2001.

SILVA, Mozart Linhares da. Educação, etnicidade e preconceito no Brasil. Santa Cruz do Sul: EDUNISC, 2007.

SILVEIRA, Rosa Maria Hessel. A entrevista na pesquisa em educação: uma arena de significados. In: COSTA, Marisa V. (Org). Caminhos Investigativos II: outros modos de pensar e fazer pesquisa em educação. Rio de Janeiro: DP\&A, 2002. p.119-142.

TRAMONTINI, Marcos Justo. A escravidão na colônia alemã: São Leopoldo - primeira metade do século XIX. In: PRIMEIRAS JORNADAS DE HISTÓRIA REGIONAL COMPARADA, 2000, Porto Alegre. Anais... Porto Alegre: FEE, 2000. Disponível em: $<$ http://cdn.fee.tche.br/jornadas/1/s5a3.pdf $>$. Acesso em 05 ago. 2016.

UEBEL, Roberto R.; RUCKERT, Aldomar A. Perfil imigratório do Estado do Rio Grande do Sul. Revista 
Signos, Lajeado, v. 37, n.2, p. 124-156, 2016.

VEIGA-NETO, Alfredo. Dominação, violência, poder e educação escolar em tempos de império. In: RAGO, Margareth e VEIGA-NETO, Alfredo (Org.). Figuras de Foucault. 3.ed. Belo Horizonte: Autêntica, 2013. p. 13-38.

VEIGA-NETO, Alfredo. Foucault \& Educação. 3. ed. Belo Horizonte: Autêntica, 2014.

WANDERER, Fernanda. Educação Matemática, jogos de linguagem e regulação. São Paulo: Editora Livraria da Física, 2014.

WESCHENFELDER, Viviane. A produção do sujeito negro: uma analítica das verdades que circulam em Venâncio Aires. 2012. 172 f. Dissertação (Mestrado) - Programa de Pós-Graduação em Educação, Universidade do Vale do Rio dos Sinos, São Leopoldo, 2012.

WITT, Marcos Antônio. Sobre escravidão e imigração: relações interétnicas. História: Debates e Tendências, Passo Fundo, v. 14, n. 1, p. 21-35, 2014.

\section{Revisores}

Língua Portuguesa

Língua Inglesa

Língua Espanhola
Rafaela Thomaz

E-mail: rafaelathomaz@hotmail.com.br

Rafaela Thomaz

E-mail: rafaelathomaz@hotmail.com.br

Rafaela Thomaz

E-mail: rafaelathomaz@hotmail.com.br 